\title{
What Are the Sources of Organizational Change Capability? The Role of Transformational Leadership and Organizational Justice
}

\author{
Tung Thanh $\mathrm{Ha}^{1}$ \& Phong Ba Le ${ }^{1}$ \\ ${ }^{1}$ Hanoi University of Industry, Bactuliem, Hanoi, Vietnam \\ Correspondence: Phong Ba Le, Hanoi University of Industry, Bactuliem, Hanoi, Vietnam.
}

Received: January 6, 2021

Accepted: February 20, 2021

Online Published: March 5, 2021

doi:10.5430/ijba.v12n2p76

URL: https://doi.org/10.5430/ijba.v12n2p76

\begin{abstract}
The paper aims to clarify the influences of transformational leadership (TL) and aspects of organizational justice on change capacity of organizations. Structural equation modelling is applied to test the relationship among the research factors based on the survey of 315 employees in 72 Vietnamese firms. The results show aspects of organizational justice act as mediating roles in the relationship between TL and organizational change capacity. TL has greater effects on innovative culture, while organizational justice has greater effects on capable champions. This study highlights the importance of building the environment of justice in an organization to link TL and organizational change capacity. This study has provided valuable initiatives and deeper insights on the new and effective pathways for firms to improve their change competence and response more successfully and rapidly towards the shift of competitive context and business environment.
\end{abstract}

Keywords: transformational leadership, organizational justice, organizational change capability, capable champions, innovative culture

\section{Introduction}

Before the rapidly change and difficult to predict of business environment and competitive pressure (Phong et al., 2017; Nguyen et al., 2019; Lei et al., 2019, Le, 2020), firm's capability of change and innovation considers key approach to response effectually with the swift alteration of environment and attain competitive advantage (Hui et al., 2018; Van et al., 2018; Phong et al., 2018; Lei et al., 2021). Firms have invested a lot of financial and non-financial resources to improve their ability to change and innovate, but it seems not to bring satisfactory results (Le, 2020; Lei et al., 2021a). Firms sometime fail for poor change management and lack of change leadership practices (Judge, 2011; Lei et al., 2019). Scholars pointed out that to overcome the key competitors, improving firms' change and innovation capabilities are essential and ongoing (Foster, 2010; Le et al., 2020; Lei et al., 2021b; Son et al., 2021). Therefore, it is necessary to continuously explore more new dimensions/factors that may foster firm's capability for change and change management (Yasir et al., 2016; Lei et al., 2019). Prior studies revealed that to build organizational change capacity (OCC) successfully, leadership and organizational change agents play an extremely important role (Judge, 2011; Lei et al., 2019a; Sengphet et al., 2019). Based on such situation, we decide to study the leader style's influences on OCC. Among different leadership style, transformational leadership (TL) is seen as one of the most effective leadership styles for effectively managing processes of change and innovation (Yasir et al., 2016; Le Ba, 2018; Lei et al., 2020). Besides, TL is regarded as the key factor that induce the positive and significant impacts on organizational justice (Wu et al., 2012; Le \& Lei, 2017; Nguyen et al., 2019), which in turn considerably influences OCC (Rafferty et al., 2013). So, this article focuses on investigate organizational justice in the relationship with TL and OCC as it has been proven to be predictive a higher levels of openness to change, acceptance of change, cooperation with change, satisfaction with change situations and plays a significant role in many organizational dynamics related to change and leader-follower relationships (Foster, 2010).

Previous studies supported the significant relationship between TL and OCC (Yasir et al., 2016; Lei et al., 2019); or the relationship between organizational justice and organizational change (Foster, 2010; Rafferty et al., 2013). However, there has been a scarcity of research on how leadership connects with aspects of organizational justice and two key elements of OCC, that is, capable champions and innovative culture (Lei et al., 2019). So, it limited our understanding of the different ways transformational leaders may build and create a justice in the organization and influences OCC effectively. In this context, it requires further theoretical or practical evidence to solidify the 
relationship of these structures. Moreover, previous studies showed that organizational justice is a critical concept/issue in modern management. Fostering organizational justice can bring significant effects on firm's performance, sustainability and key outcomes (Akram et al., 2020). Even so, there is little study on the antecedents and consequences of organizational justice (Akram et al., 2020; Phong and Son, 2020). Thus, examining the direct influence of organization justice as well as its mediating effects between TL and aspects of change capability has important implications in enhancing our understanding of the role of justice in organizations. Therefore, our study was done to explore TL's impacts on OCC through mediating the role of distributive, procedural and interactional justice. This study is expected to contribute to increasing the knowledge of how TL and organizational justice induce significant influence on OCC. This study attempts to address the following research questions (see Figure 1).

RQ1. Does TL have significant influences on OCC?

RQ2. How different are TL's influences on innovative culture and capable champions?

RQ3. Do aspects of justice have mediating role between TL and OCC?

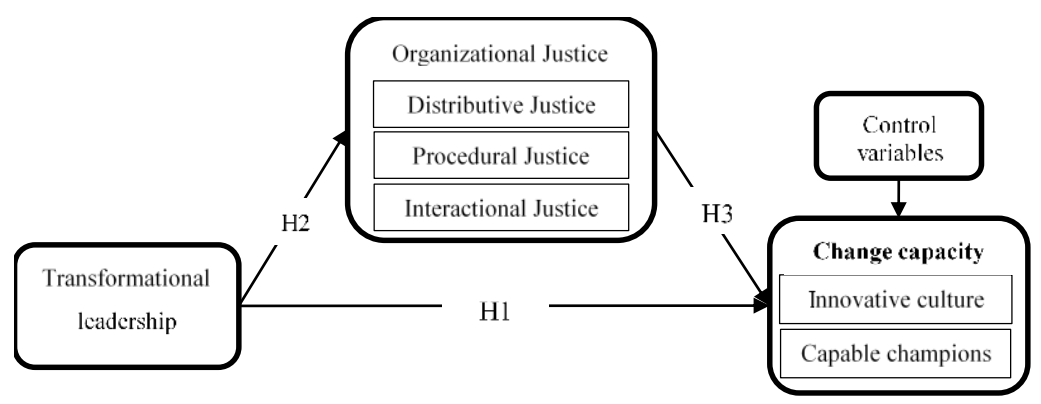

Figure 1. Research model

To answer above questions, structural equations modelling (SEM) is applied to investigate the degree of influence each variable has on each other based on a survey of 315 participants from 72 Vietnamese firms. The remainder of this study is arranged as follows. Part 2 presents the literature review for the concepts in the proposed model, and develops a research model to portray the hypothesized relationship. Part 3 provides research methods for testing the model and data collection. Part 4 analyses the data and discusses the empirical result. Finally, this study gives some conclusions, managerial implications, its limitations and makes proposals for future research in Part 5.

\section{Literature Review}

\subsection{TL and Organizational Change Capability}

Change capability is defined as the combination of managerial and organizational competence that enables enterprises to response more rapidly and productively before the changing of business environment (Lei et al., 2019). According to Soparnot (2011), OCC is the key ability of a firm to initiate and execute successfully activities for dealing with difficult situations. It plays a critical role in bringing sustainable development for organizations in competitive and integrated environment. Change capability is formed by many elements, however, Lei et al. (2019) indicated that capable champions and innovative culture serve as two key components of OCC because they reflect the root and nature of organizational capacity for change (Judge and Douglas, 2009). Innovative culture refers capabilities of a firm to set up the necessary norms for innovation and stimulate a culture of change and innovation in an organization; while capable champions reflects firm's abilities to attract, retain, and empower change leaders to organize and implement the necessary change (Lei et al., 2019).

TL is defined as the style of leadership that characterizes leaders who emphasize clarity in their communications about organizational goals; act as the organization's leading force; engage in active coaching; promote new skill development among their followers and continuously seek new opportunities for their organization development (Le \& Lei, 2017; Hui et al., 2018; Le \& Lei, 2018a; Van et al., 2018). Transformational leaders consider employees as a valuable resource in the firm and emphasize the important role of emotions, values, and leadership oriented to encouraging positive and creative behaviors (Bass \& Avolio, 2000; Phong \& Son, 2020). According to Bass (1985), transformational leaders could motivate and inspire employees to execute beyond expectations and help them reach 
their full potential for an organization. The theory of TL has attracted great attention from scholars and become one of the most dominant leadership theories (Mhatre \& Riggio, 2014; Le \& Tran, 2020). So, exploring influences of TL on OCC plays a crucial role in finding an effective way to promote organizational capacity for change.

Current literature has supported the critical role of transformational leaders in fostering both process of idea formation and implementation for change and innovation (Lutz Allen et al., 2013; Lei et al., 2021). According to Chen et al. (2013) and Lei et al. (2019), transformational leaders pay great attention on promoting processes of sharing new knowledge and skills among employees, fostering a culture of trust and collaboration, and continuously seeking new opportunities for fostering the change and development for their organization. Lutz Allen et al. (2013) pointed out that in case of applying and practicing TL style, supervisors and managers can have more chance to successfully manage and implement the important change for organizations. In particular notes, scholars highlight that TL style is one of the most relevant or applicable for achieving the desired results on change and innovation (Yasir et al., 2016; Lei et al., 2019). To explore more deeply influences of TL on capable champions and innovative culture, the following hypothesis is tested:

\section{Hla.b: TL has positive impacts on OCC in terms of innovative culture and capable champions.}

\subsection{TL and Organizational Justice}

Organizational justice is an important issue in the field of leadership (Pillai et al. 1999). Justice basically based upon individuals' perceptions that take place within the exchange relationship, simultaneously emphasizes their perceptions about the repaying an obligation that they owed others (Caldwell et al. 2001; Le Ba, 2018; Lei et al., 2019; Phong \& Son, 2020). According to Afzalur Rahim et al. (2001), organizational justice contains three basic aspects/components namely procedural, distributive and interactional justice. Distributive justice is the most commonly recognized as the type of justice reflecting the perceptions of outcome's fairness that employees receive; procedural justice refers to be aware of fairness about procedures or processes used to determine those outcomes, in which the procedures are presented by activities such as performance assessment, rewards and opportunities sharing; and interactional justice refers to the employees' perceptions of the fairness of the interpersonal treatment by decision makers in the organization's working environment (Zainalipour et al. 2010; Phong \& Son, 2020).

The correlation between TL and justice received little research attentions, some previous researches have also indicated the positive relationship among them (e.g., Tyler \& Caine, 1981; Pillai et al., 1999; Kirkman et al., 2009; Lei et al., 2019). Tyler and Caine (1981) supposed that transformational leaders create opportunities for followers to manifest their opinions which were viewed as a fair practice from followers' viewpoint. In case of not pay attention to the fairness, leaders will be rejected leadership authority by followers. Pillai et al. (1999) and Kirkman et al. (2009) argued that, leaders have decisive influences on employees' perceptions of justice (such as: procedural, distributive and interactional justice). Especially, some empirical studies have verified for the positive effects of leadership on procedural, distributive and interactional justice. Indeed, Pillai et al. (1999) showed strong and positive relationship between TL and procedural justice. De Cremer et al. (2004) showed that, positive leadership styles (such as self-sacrifice) have significant influences on employees' attitudes and distributive justice. Wu et al. (2012) proved positive influences of benevolent leadership on perceived interactional justice.

Above arguments give the support for the TL's positive influences on aspects of organizational justice However, research that analyzed simultaneously these factors in a model is still scarce and limited. To explore TL's different effects on distributive, procedural and interactional justice, following hypotheses are proposed.

H2a.b.c: TL has a positive impact on distributive, procedural and interactional justice.

\subsection{Organizational Justice and Change Capability}

The relationship between organizational justice and change capability received little attention from researchers. However current literature also showed the positive effects of organizational justice on OCC. Indeed, Mishra \& Spreitzer (1998) stated that individual's perceptions of the fairness of the decisions and implementing the change may affect both their cooperation with the change and their evaluations of the parties responsible for the change. After performing a progress of literature review on organizational justice and employee reactions to organizational change, Oreg and van Dam (2009) found that justice is considered as an antecedent of change reactions. Individuals' perceptions of justice was positively related to OCC as individuals who felt that the outcomes or/and procedures were equitably and without bias, would have a positive support/reaction and strong commitment to change situations (Bernerth et al., 2007; Oreg et al., 2011), conversely, the perceptions or anticipations of injustice would be associated with negative reactions to the change situations (Oreg \& van Dam, 2009; Oreg et al., 2011). Rodell and Colquitt's (2009) results of a longitudinal study in a hospital showed that interactional justice was positively related to 
employee's support for the change. Foster (2010) stated that change efforts often stir up unpredicted challenges, and employee responses to changes ultimately determine the degree success of change efforts. Foster (2010) also proved that aspects of organizational justice (namely: distributive, procedure and interactional justice) have positive and great influences on individual's affective and normative commitment to change situations.

In summary, above arguments provide supports for significant impacts of organizational justice on OCC. Nevertheless, to my knowledge, to date have no study exploring the different impacts of the relationship between three aspects of justice and specific elements of OCC. Hence, this paper expects to have positive contribution to developing change literature by testing the following hypotheses.

H3a.b.c: Distributive, procedural and interactional justice has positive impacts on innovative culture.

H3d.e.f: Distributive, procedural and interactional justice has positive impacts on capable champions.

\section{Research Methodology}

\subsection{Sample and Data Collection}

In summer 2020, empirical data were collected through a survey of 72 Vietnamese firms in some most developed provinces of Vietnam. To meet research needs, the respondents in this study need to be directors, managers, head of department, and key staffs in the departments of administration, operation, accounting, planning, and R\&D to ensure that they have fully understanding on the key issues in their organizations. The measurement items are adapted from exiting scales in the literature for developing an initial list of items. This study issues 650 questionnaires and receives 400 valid copies, among which 315 ones were valid (48.5\% validity rate). Potential non-response bias was assessed by following the method proposed by Armstrong and Overton (1977). Chi-square and independent sample $t$-test were used to compare the earlier 80 respondents and the last 80 ones based on demographic variables, including gender, age, and level of education. The results demonstrated that there were no significant differences between the two groups of responses $(p>0.05)$. Therefore, it showed that common method bias was not a concern. A total of 315 respondents $196(62.2 \%)$ were male and $119(37.8 \%)$ were female. They answered the questions relating to the study variables: TL, organizational justice, innovative culture and capable champions.

\subsection{Variable Measurement}

To ensure the validity and reliability of the study, items used to measure variables that have been developed and used from previous studies. All constructs were measured using multiple items and all items are measured via five-point Likert-type scales, ranging from ' 1 ' (strongly disagree) to ' 5 ' (strongly agree); or from ' 1 ' (not at all) to ' 5 ' (frequently). Specifically, for measuring transformational leadership, this study used four items designed by Podsakoff et al. (1996) for diverse aspects of TL. These items were used in the research of Le and Lei (2018) to reflect participant's perceptions of their leader about TL style. A sample items is "my supervisors are capable of motivating and guiding their colleagues on the job".

In order to measure distributive, procedural and interactional justice, this study used eleven items (three items per component) adapted from the research of Rahim et al. (2001). A sample item of distributive justice is "I believe that my rewards appropriately reflect my contributions to the organization"; a sample item of procedural justice is "My organization has in place formal channels that allow employees to express their views and opinions before decisions are made"; and a sample item of interactional justice is "My supervisor treats me in a kindly manner".

Finally, this study utilized eight items derived from the studies of Judge and Douglas (2009) to take the measurements of capable champions and innovative culture. Innovative culture is measured by four items reflecting the firm's ability to establish norms of innovation as well as encourage innovative activity and change. A sample item is "Do we have an organizational culture that values innovation and change?"; Capable champions are measured by four items reflecting the firm's ability to attract, retain, and empower change leaders to evolve and emerge. A sample item is "Do we have change champion(s) who have the will and creativity to bring about change?" In addition, this study considers demographic variables (such as education level, gender, working position and working experience) as control variables to account for differences among firms and their potential impacts on OCC.

\subsection{Data Analysis Methods}

Analysis of Moment Structures (AMOS) was employed for measurement validation and for testing the structural model based on the data gathered from the 315 respondents in 72 service and manufacturing firms in Vietnam. Data analysis was conducted by using SPSS and AMOS version 22. Confirmatory factor analysis (CFA) was implemented to examine the validity and reliability of the constructs. Besides, a bootstrapping procedure is conducted for testing the significance of the research hypotheses. 


\section{Data analysis and Results}

\subsection{Measurement Model}

We first tested the reliability of the measures for the constructs by examining the Cronbach's alpha coefficients $(\mathrm{C} \alpha)$ of each construct, the statistic findings range from 0.84 to 0.94 and exceed Nunnally and Bernstein's (1994) recommended level of 0.7 . We then implemented the analysis of confirmatory factor (CFA) for estimating convergent and discriminant validity of overall measurement model.

The findings from confirmatory factor analysis indicates that all factor loadings range from 0.70 to 0.98 (all larger than 0.6) being statistically significant at the 0.001 level; CR values (ranging from 0.84 to 0.95 ) are higher than 0.7 ; and the AVE values range from 0.58 to 0.83 (all greater than 0.5). Overall, all the measures exhibited adequate convergent validity. Table 1 shows the means, standard deviation (SD), factor loading, AVE, CR and C $\alpha$ of every construct.

Table 1. Reliability, correlations and average variances extracted from constructs

\begin{tabular}{llllllllllll}
\hline Constructs & Mean & SD & AVE & CR & C $\alpha$ & TL & DJ & PJ & IJ & IC & CC \\
\hline TL & 3.47 & 0.52 & 0.58 & 0.84 & 0.84 & $\mathbf{0 . 7 6}$ & & & & & \\
\hline DJ & 3.53 & 0.54 & 0.82 & 0.93 & 0.93 & 0.48 & $\mathbf{0 . 9 0}$ & & & & \\
\hline PJ & 3.51 & 0.65 & 0.69 & 0.90 & 0.89 & 0.63 & 0.48 & $\mathbf{0 . 8 3}$ & & & \\
\hline IJ & 3.52 & 0.56 & 0.81 & 0.94 & 0.94 & 0.52 & 0.42 & 0.57 & $\mathbf{0 . 9 0}$ & & \\
\hline IC & 3.75 & 0.57 & 0.75 & 0.92 & 0.92 & 0.65 & 0.49 & 0.61 & 0.59 & $\mathbf{0 . 8 6}$ & \\
\hline CC & 3.70 & 0.62 & 0.83 & 0.95 & 0.95 & 0.63 & 0.51 & 0.46 & 0.60 & 0.57 & $\mathbf{0 . 9 1}$ \\
\hline
\end{tabular}

Note: Notes: $C \alpha \geq 0.7$; composite reliability $\geq 0.7$; average variances extracted $\geq 0.5$;Diagonal elements (in bold) are the square root of the AVE

Discriminant validity is the degree to which, factors that are supposed to measure a specific construct do not predict conceptually unrelated criteria (Kline, 2010). This study used Fornell and Larcker's (1981) measure of average variance extracted to assess the discriminant validity. In this approach, the discriminant validity of the research instrument was assessed by comparing the square root of the AVE with the correlations among the latent variables. Table 1 shows that the square root of AVE for each construct (diagonal elements in bold) is greater than the correlations among constructs in the model. In general, the results provide strong support for the construct reliability, as well as for the convergent and discriminant validity of the scales.

We assessed the measurement model fit by evaluating: absolute fit measures including Chi-square/df (CMIN/df), goodness of fit index (GFI) and root mean square error of approximation (RMSEA); incremental fit measures including normed fit index (NFI), adjusted goodness of fit index (AGFI) and comparative fit index (CFI). Table 2 shows the measure model fit. As shown in Table 2, all fit indices met satisfactory levels. Hence we can conclude that, the model fits the data and can explain the research hypotheses.

Table 2. Overall fit index of the CFA model

\begin{tabular}{lll}
\hline Fit index & Scores & Recommended threshold value \\
\hline Absolute fit measures & & \\
\hline CMIN/df & 1.514 & $\leq 2^{\mathrm{a}} ; \leq 5^{\mathrm{b}}$ \\
\hline GFI & 0.911 & $\geq 0.90^{\mathrm{a}} ; \geq 0.80^{\mathrm{b}}$ \\
\hline RMSEA & 0.040 & $\leq 0.08^{\mathrm{a}} ; \leq 0.10^{\mathrm{b}}$ \\
\hline Incremental fit measures & & \\
\hline NFI & 0.946 & $\geq 0.90^{\mathrm{a}} ;$ \\
\hline AGFI & 0.881 & $\geq 0.90^{\mathrm{a}} ; \geq 0.80^{\mathrm{b}}$ \\
\hline CFI & 0.981 & $\geq 0.90^{\mathrm{a}} ;$ \\
\hline
\end{tabular}

Note: a Acceptability: acceptable; b Acceptability: marginal. 


\subsection{Structural Model}

This section presents the main result of the hypothesis testing of the structural relationship among the latent variables (Figure 2, Table 3, and Table 4).

\subsubsection{Direct Effect Analysis}

The findings from structural model (Figure 2 and Table 3) support the direct effects of TL and organizational justice on change capability with reliable statistical significance levels. All the hypotheses, thus, are supported. Specifically:

For hypothesis H1a.b, the results confirmed the positive and significant impacts of TL on aspects of OCC. Specifically, TL has greater impacts on innovative culture (coefficient value $0.381 ; p$ value $<0.001$ ) in comparison with TL's influences on firm's capable champions (coefficient value $0.241 ; p$ value $<0.001$ ).

For hypothesis H2a.b.c, the results revealed that TL's influences on organizational justice are very strong. Specifically, TL's has the most impacts on procedural justice (coefficient value $0.687 ; p$ value $<0.001$ ) in comparison with interactional justice (coefficient value $0.582 ; p$ value $<0.001$ ) and distributive justice (coefficient value $0.538 ; p$ value $<0.001$ ).

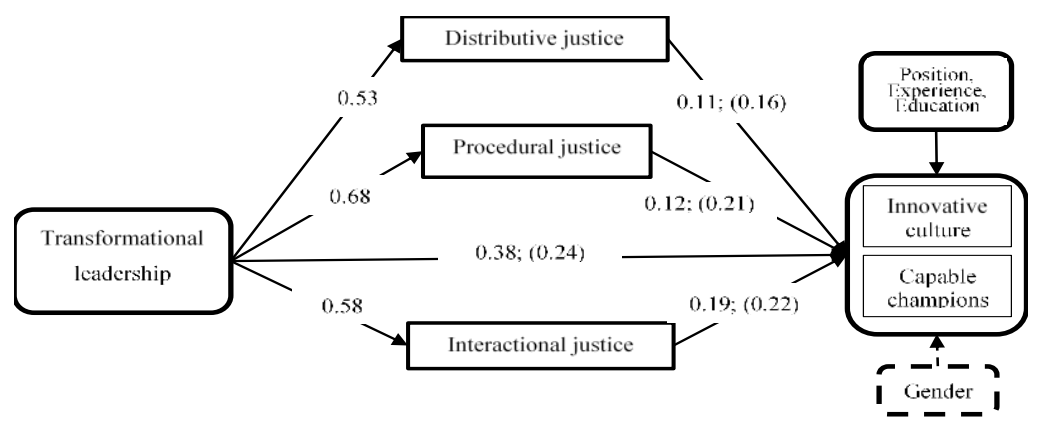

Figure 2. Path coefficients of the structural model

Note: Estimate of impacts on capable champions in parentheses; ----- Non-significant paths.

Table 3. Structural model results

\begin{tabular}{lclll}
\hline Hypotheses & Proposal effect & Estimate & $p$ & Results \\
\hline H1a: TL $\rightarrow$ Innovative culture & + & $0.381^{* * *}$ & $<0.001$ & Supported \\
\hline H1b: TL $\rightarrow$ Capable champions & + & $0.241^{* *}$ & 0.007 & Supported \\
\hline H1c: TL $\rightarrow$ Distributive justice & + & $0.538^{* * *}$ & $<0.001$ & Supported \\
\hline H2b: TL $\rightarrow$ Procedural justice & + & $0.687^{* * *}$ & $<0.001$ & Supported \\
\hline H2b: TL $\rightarrow$ Interactional justice & + & $0.582^{* * *}$ & $<0.001$ & Supported \\
\hline H3a: DJ $\rightarrow$ Innovative culture & + & $0.114^{* *}$ & 0.033 & Supported \\
\hline H3b: DJ $\rightarrow$ Capable champions & + & $0.163^{* *}$ & 0.002 & Supported \\
\hline H3c: PJ $\rightarrow$ Innovative culture & + & $0.122^{*}$ & 0.078 & Supported \\
\hline H3d: PJ $\rightarrow$ Capable champions & + & $0.215^{* *}$ & 0.001 & Supported \\
\hline H3e: IJ $\rightarrow$ Innovative culture & + & $0.191^{* *}$ & $<0.001$ & Supported \\
\hline H3f: IJ $\rightarrow$ Capable champions & + & $0.202^{* * *}$ & $<0.001$ & Supported \\
\hline Control variables & Effect & Estimate & P & Results \\
\hline WP $\rightarrow$ Innovative culture & + & $0.111^{* *}$ & 0.010 & Supported \\
\hline WP $\rightarrow$ Capable champions & + & $0.083^{* *}$ & 0.048 & Supported \\
\hline WE $\rightarrow$ Innovative culture & + & $0.157^{* * *}$ & $<0.001$ & Supported \\
\hline
\end{tabular}




\begin{tabular}{lllll}
\hline WE $\rightarrow$ Capable champions & + & $0.158^{* * *}$ & 0.002 & Supported \\
\hline $\mathrm{RG} \rightarrow$ Innovative culture & - & -0.018 & 0.667 & Not supported \\
\hline $\mathrm{RG} \rightarrow$ Capable champions & + & 0.001 & 0.975 & Not supported \\
\hline $\mathrm{RE} \rightarrow$ Innovative culture & + & $0.107^{* *}$ & 0.012 & Supported \\
\hline $\mathrm{RE} \rightarrow$ Capable champions & + & $0.209^{* * *}$ & $<0.001$ & Supported \\
\hline
\end{tabular}

Note: $* * * p<0.001 ; * * p<0.05 ; * p<0.10$.

For hypothesis H3a.b.c.d.e.f, the results show that, all three aspects of justice have greater impacts on capable champions compared with innovative culture. Specifically, distributive justice influences innovative culture and capable champions with coefficient value $0.114(p$ value $=0.033)$ and $0.163(p$ value $=0.002)$. Procedural justice influences innovative culture and capable champions with coefficient value is $0.122(p$ value $=0.078)$ and $0.215(p$ value $=0.001)$. Interactional justice influences capable champions and innovative culture with coefficient value is 0.202 ( $p$ value $<0.001)$, and 0.191 ( $p$ value $<0.001)$, respectively.

The results of the proposal hypothesis assessments were acquired after examining the controlling roles of working position, working experience, level of education, and gender of employees. Excluding the impact of gender, the consequences from Table 3 and Figure 2 have supported the control role of working position, working experience, level of education of employees.

\subsubsection{Indirect and Total Effect Analysis}

Our study does not just give evidence about the influence of TL on OCC; it also shows how this mechanism is activated through aspects of organizational justice. The indirect effects and total effects are computed and listed in Table 4. To provide evidence on the mediating roles of organizational justice in the relationship between TL and OCC, this study implements further analyses to verify the magnitude and the statistical significance of the indirect effects. For statistical inferences as the suggestion of Preacher and Hayes (2008), we used the bootstrap confidence intervals method with 1,000 iterations to test the significance of indirect effects (see Table 4).

Table 4. Direct, indirect and total effects analysis

\begin{tabular}{llllll}
\hline \multirow{2}{*}{ Path } & Direct effects & $\begin{array}{l}\text { Indirect } \\
\text { effects }\end{array}$ & $\begin{array}{l}\text { Total } \\
\text { effects }\end{array}$ & & \multicolumn{2}{l}{$\begin{array}{l}\text { Bias-corrected confidence intervals } \\
\text { confidence level }\end{array}$} & $\begin{array}{l}\text { Upper } \\
\text { confidence level }\end{array}$ \\
\hline $\mathrm{TL} \rightarrow$ Justice $\rightarrow \mathrm{IC}$ & $0.381^{* * *}$ & $0.256^{* *}$ & 0.637 & 0.118 & 0.393 \\
\hline $\mathrm{TL} \rightarrow$ Justice $\rightarrow \mathrm{CC}$ & $0.241^{* * *}$ & $0.354^{* *}$ & 0.595 & 0.232 & 0.475 \\
\hline
\end{tabular}

Note: $* * * \mathrm{p}<0.001$ level; $* * \mathrm{p}<0.005$ level.

Table 4 showed indirect influence of TL on capable champions and innovative culture have coefficient values are 0.354 and 0.256 (which were in confidence intervals) with $p$ value less than 0.005 . It exhibited the indirect impact of $\mathrm{TL}$ on OCC through the aspects of organizational justice. So, as to the indirect effects, Table 4 firstly confirms the mediating role of distributive, procedural and interactional justice in the relationships between TL and two components of OCC. Besides, the results showed total effects of TL on innovative culture are very impressive with value of 0.637 . It is due to TL's direct effect on innovative culture is very significant with coefficient value $0.381(p$ value $<0.001$ ).

\section{Discussions and Implications}

In the era of industrial revolution 4.0, change capability and the method to effectively and rapidly response to change contexts are becoming a crucial matter in the leaders' concerns (Ramezan et al., 2013; Nguyen et al., 2018). Scholars reveal that leaders and organizations are digesting tens of millions dollars for change activities, but it seems ineffective (Ramezan et al., 2013; Lei et al., 2019). Primary reasons explain for these non-fulfillment originated from the fact that, top managers have not yet recognized the effective pathway to effectively improve their organizational change capability. Meanwhile, the success degree of performing the initiatives on change and innovation mainly 
depends on the leader's capability to recognize the antecedents and conditions for stimulating changes ad innovation (Bossidy et al., 2011; Lei et al., 2021). In this context, the hypotheses that were developed in this article makes important contributions to both practical and theoretical initiatives on change management and leadership as follows.

First, by assessing two specific component of OCC in relationship with the other constructs in the hypothesis model, our study makes considerable contributions to the development of OCC initiatives. As capable champions and innovative culture manifest two basic aspects of change competence. Indeed, innovative culture allows firms to fomulate a prime spirit and foundation to nurture the change; and capable champions enable firms to turn idea of change into a fruitful reality. Such perspectives are more accomplishable and feasible for CEOs and leaders to improve and obtain change competence in comparison with Judge \& Douglas's (2009) multi-dimensional assessment tool to diagnose and guide organizational change.

Second, the article contributes to increasing the understanding of the relationship between TL, organizational justice and OCC by conducting a complete review of current literatures of these constructs and indicates TL's significant influences on aspects of justice and OCC. The basic reason may be due to TL is one of the most effective leadership styles (Thomson et al., 2016). Regaring to the relationship between TL, justice and specifics aspects of OCC, the finding revealed that TL has greater impacts on innovative culture in comparison with capable champions. In contrast, all aspects of justice have greater impacts on capable champions in compared with innovative culture. Identifying relationships among structures provides specific and useful guides for the directors/managers to have the desired impacts on each part of OCC. Based on the findings, the article implied that: positive characteristics of transformational leaders (such as pay more attention to communicate about organizational goals, act as the organization's leading force, and continuously seek new opportunities for their organization development) seem to have greater influences on innovative culture in comparison with its influences on capable champions, so directors/managers should pay great attention on practicing TL aiming at stimulating innovative culture of an organization. While building and implementing aspects of justices in the organization to enhance individuals' awareness of justice will positively influence capable champions.

Third, Kark Smollan (2006) found that when people are faced with changes to some aspect of their working lives they respond on a number of levels: cognitive, affective and behavioral. So an effective way to improve OCC is that basing on enhancing cognitive, affective and behavioral responses of individuals towards change, that can be attained by building and establishing the justice at all aspects. Besides, Foster (2010) implied that, awareness and application of fairness in the workplace are very necessary to consolidate leader-employee relationships that also benefit for both organizations and employees. By assessing the influences of TL on three aspects of justice and OCC, the article, therefore, makes considerable contribution to build up a justice framework which applied to areas of work and organizational psychology aiming at improving organizational capacity for change.

Fourth, the empirical findings verified the mediating roles of two aspects of justice and highlight that TL practices will yield significant effects to OCC directly or indirectly through improving aspects of organizational justice. Moreover, by investigating the impacts of controlling factors, the finding of this study denoted that employees' working position, working experience, and level of education have significant effect on change capability of organizations. From these findings, some practical suggestions are prefered for CEOs/managers as follows: (1) caring for improving organizational change comptency through strengthening training and retraining programs; (2) paying great attention and encouraging new ideas and perspectives of experienced employees; and (3) increasing the perceptions of key leaders on the necessity towards change and innovation for long-term organizational development.

Besides, significant contributions, the paper has also contained some restrictions. First, this study applied the cross-sectional design, therefore, it may appear ability that causal relationships may change in the long term. More studies need to be implemented in the long term to address this restriction and verify the results. Second, the findings and the patterns from this article are appropriate especially for the situation of firms in Vietnam. Future works may carry out in other cases to furnish a clearer insight on the correlation among these latent factors. Third, capable champions and innovative culture are shown as two key ingredients of organizational change capability. Thus, it is important to implement more studies in future to link them with the key outcomes of organizations (such as organizational performance, strategic performance and competitive advantage) to provide a full awareness of the important role and effects of capable champions and innovative culture. Fourth, organizational justice is emerging as a critical approach in modern management by which firms can nurture organizational justice to improve firm's key outcomes (Akram et al., 2020; Phong and Son, 2020). Consequently, future research should investigate the direct influence of organization justice as well as its mediating effects between TL and aspects of organizational 
performance such as operational performance and innovation performance to increase our understandings on the role of justice in organizations. Finally, theory of leader-member exchange (LMX) is regarded as one of the most remarkable theories for dealing with the leadership-employee relationship in organizations (Aggarwal et al., 2020), future research might analyze and examine the mediating role of justice between LMX and element of organizational change capability or key outcomes to advance the understanding the theory of leadership and organizational justice.

In general, this study has significantly provided both theoretical and practical significance due to its significant implications for scholars and practitioners in the process of making plans and implementing change initiatives. In other words, the paper has shown the new pathways for firms to follow and improve their change capacity aimed to response more effectively towards the context of change from business environment and achieve sustainable competitive advantage.

\section{References}

Afzalur Rahim, M., Magner, N. R., Antonioni, D., \& Rahman, S. (2001). Do justice relationships with organization-directed reactions differ across US and Bangladesh employees?. International Journal of Conflict Management, 12(4), 333-349. https://doi.org/10.1108/eb022862

Aggarwal, A., Chand, P. K., Jhamb, D., \& Mittal, A. (2020). Leader-member exchange, work engagement, and psychological withdrawal behavior: the mediating role of psychological empowerment. Frontiers in Psychology, 11. https://doi.org/10.3389/fpsyg.2020.00423

Akram, T., Lei, S., Haider, M. J., \& Hussain, S. T. (2020). The impact of organizational justice on employee innovative work behavior: Mediating role of knowledge sharing. Journal of Innovation \& Knowledge, 5(2), 117-129. https://doi.org/10.1016/j.jik.2019.10.001

Bass, B. M. (1985). Leadership and performance beyond expectations. Free Press, Collier Macmillan.

Bass, B. M., \& Avolio, B. J. (2000). MLQ: Multifactor leadership questionnaire. Mind Garden.

Bernerth, J. B., Armenakis, A. A., Field, H. S., \& Walker, H. J. (2007). Justice, cynicism, and commitment: A study of important organizational change variables. The Journal of Applied Behavioral Science, 43(3), 303-326. https://doi.org/10.1177/0021886306296602

Bossidy, L., Charan, R., \& Burck, C. (2011). Execution: The discipline of getting things done. Random House.

Caldwell, C., Campbell, J., \& Parks, C. (2001). Trustworthiness and justice-An integrative perspective. Paper presented at the Eighth Annual Conference on Ethics in Business, Chicago, IL, October.

Chen, Y., Jermias, J., \& Lee, G. (2013). The performance implication of goal achievability in incentive contracts and feedback. Paper presented at the CAAA Annual Conference. https://doi.org/10.2139/ssrn.2200275

Fornell, C., \& Larcker, D. F. (1981). Evaluating structural equation models with unobservable variables and measurement error. Journal of Marketing Research, 39-50. https://doi.org/10.1177/002224378101800104

Foster, R. D. (2010). Resistance, justice, and commitment to change. Human Resource Development Quarterly, 21(1), 3-39. https://doi.org/10.1002/hrdq.20035

Ha, A. T. L., Phong, L. B., \& Hui, L. (2019). Leadership and organizational learning: the determinants of innovation speed and innovation quality in vietnamese firms. Journal of Management and Strategy, 10(1), 29-37. https://doi.org/10.5430/jms.v10n1p29

Hair, J. F., Black, W. C., Babin, B. J., Anderson, R. E., \& Tatham, R. L. (2006). Multivariate data analysis (6th ed.). New Jersey: Pearson Education.

Higgs, M., \& Rowland, D. (2011). What does it take to implement change successfully? A study of the behaviors of successful change leaders. The Journal of Applied Behavioral Science, 47(3), 309-335. https://doi.org/10.1177/0021886311404556

Hui, L., Phouvong, S., \& Phong, L. B. (2018). Transformational leadership facilitates innovation capability: the mediating roles of interpersonal trust. International Journal of Business Administration, 9(3), 1-9. https://doi.org/10.5430/ijba.v9n3p1

Judge, W. Q. (2011). Building organizational capacity for change: The leader's new mandate. Business Expert Press. https://doi.org/10.4128/9781606491256

Judge, W., \& Douglas, T. (2009). Organizational change capacity: the systematic development of a scale. Journal of Organizational Change Management, 22(6), 635-649. https://doi.org/10.1108/09534810910997041 
Kirkman, B. L., Chen, G., Farh, J. L., Chen, Z. X., \& Lowe, K. B. (2009). Individual power distance orientation and follower reactions to transformational leaders: A cross-level, cross-cultural examination. Academy of Management Journal, 52(4), 744-764. https://doi.org/10.5465/amj.2009.43669971

Kline, R. (2010). Principles and practice of structural equation modeling (3rd ed.). Guilford Press, New York. USA.

Le Ba, P. (2018). Research on the relationship between transformational leadership and knowledge sharing: the mediating roles of justice and trust. PhD Thesis, Hunan University. https://doi.org/10.1108/JKM-10-2016-0463

Le, B. P., \& Tran, Q. T. (2020). Leadership practice for building trust of followers: decisive factors of organizational performance. SEISENSE Journal of Management, 3(2), 45-57. https://doi.org/10.33215/sjom.v3i2.308

Le, B. P., Lei, H., Phouvong, S., Than, T. S., Nguyen, T. M. A., \& Gong, J. (2018a). Self-efficacy and optimism mediate the relationship between transformational leadership and knowledge sharing. Social Behavior and Personality: an International Journal, 46(11), 1833-1846. https://doi.org/10.2224/sbp.7242

Le, P. B. (2020). How transformational leadership facilitates radical and incremental innovation: the mediating role of individual psychological capital. Asia-Pacific Journal of Business Administration, 12(3/4), 205-222. https://doi.org/10.1108/APJBA-04-2020-0129

Le, P. B., \& Lei, H. (2017). How transformational leadership supports knowledge sharing: Evidence from Chinese manufacturing and service firms. Chinese Management Studies, 11(3), 479-497. https://doi.org/10.1108/CMS-02-2017-0039

Le, P. B., \& Lei, H. (2018a). The mediating role of trust in stimulating the relationship between transformational leadership and knowledge sharing processes. Journal of Knowledge Management, 22(3), 521-537. https://doi.org/10.1108/JKM-10-2016-0463

Le, P. B., \& Lei, H. (2018b). The effects of innovation speed and quality on differentiation and low-cost competitive advantage: The case of Chinese firms. Chinese Management Studies, 12(2), 305-322. https://doi.org/10.1108/CMS-10-2016-0195

Le, P. B., \& Lei, H. (2018c). Fostering knowledge sharing behaviours through ethical leadership practice: the mediating roles of disclosure-based trust and reliance-based trust in leadership. Knowledge Management Research \& Practice, 16(2), 183-195. https://doi.org/10.1080/14778238.2018.1445426

Le, P. B., \& Lei, H. (2019). Determinants of innovation capability: the roles of transformational leadership, knowledge sharing and perceived organizational support. Journal of Knowledge Management, 23(3), 527-547. https://doi.org/10.1108/JKM-09-2018-0568

Le, P. B., Lei, H., \& Than, T. S. (2018b). How leadership and trust in leaders forster employees' behavior toward knowledge sharing. Social Behavior and Personality: An International Journal, 46(5), 705-720. https://doi.org/10.2224/sbp.6711

Le, P. B., Lei, H., Le, T. T., Gong, J., \& Ha, A. T. (2020). Developing a collaborative culture for radical and incremental innovation: the mediating roles of tacit and explicit knowledge sharing. Chinese Management Studies, 14(4), 957-975. https://doi.org/10.1108/CMS-04-2019-0151

Lei, H., Do, N. K., \& Le, P. B. (2019). Arousing a positive climate for knowledge sharing through moral lens: the mediating roles of knowledge-centered and collaborative culture. Journal of Knowledge Management, 23(8), 1586-1604. https://doi.org/10.1108/JKM-04-2019-0201

Lei, H., Gui, L., \& Le, P. B. (2021). Linking transformational leadership and frugal innovation: the mediating role of tacit and explicit knowledge sharing. Journal of Knowledge Management (In press). https://doi.org/10.1108/JKM-04-2020-0247

Lei, H., Ha, A. T. L., \& Le, P. B. (2019). How ethical leadership cultivates radical and incremental innovation: the mediating role of tacit and explicit knowledge sharing. Journal of Business \& Industrial Marketing, 35(5), 849-862. https://doi.org/10.1108/JBIM-05-2019-0180

Lei, H., Khamkhoutlavong, M., \& Le, P. B. (2021). Fostering exploitative and exploratory innovation through HRM practices and knowledge management capability: the moderating effect of knowledge-centered culture. Journal of Knowledge Management (In press). https://doi.org/10.1108/JKM-07-2020-0505 
Lei, H., Nguyen, T. T., \& Le, P. B. (2019). How knowledge sharing connects interpersonal trust and innovation capability: The moderating effect of leadership support. Chinese Management Studies, 13(2), 276-298. https://doi.org/10.1108/CMS-06-2018-0554

Lei, H., Phouvong, S., \& Le, P. B. (2019). How to foster innovative culture and capable champions for Chinese firms: an empirical research. Chinese Management Studies, 13(1), 51-69. https://doi.org/10.1108/CMS-05-2018-0502

Lutz Allen, S., Smith, J. E., \& Da Silva, N. (2013). Leadership style in relation to organizational change and organizational creativity: Perceptions from nonprofit organizational members. Nonprofit Management and Leadership, 24(1), 23-42. https://doi.org/10.1002/nml.21078

Mhatre, K. H., \& Riggio, R. E. (2014). Charismatic and transformational leadership: Past, present, and future. The Oxford Handbook of Leadership Ond 221-240. https://doi.org/10.1093/oxfordhb/9780199755615.013.012

Mishra, A. K., \& Spreitzer, G. M. (1998). Explaining how survivors respond to downsizing: The roles of trust, empowerment, justice, and work redesign. Academy of management Review, 23(3), 567-588. https://doi.org/10.5465/amr.1998.926627

Nunnally, J. C., \& Bernstein, I. (1994). Elements of statistical description and estimation. Psychometric Theory (3rd ed.).

Nguyen, D. K., Phong, L. B., \& Hui, L. (2019). Creating competitive advantage for vietnamese manufacturing and service firms: the role of collaborative culture and innovation capability. International Journal of Business Administration, 10(2), 32-42. https://doi.org/10.5430/ijba.v10n2p32

Nguyen, M. A. T., Lei, H., Vu, K. D., \& Le, P. B. (2018). The role of cognitive proximity on supply chain collaboration for radical and incremental innovation: a study of a transition economy. Journal of Business \& Industrial Marketing, 34(3), 591-604. https://doi.org/10.1108/JBIM-07-2017-0163

Oreg, S., \& Van Dam, K. (2009). Organisational justice in the context of organisational change. Netherlands Journal of Psychology, 65(4), 127-135. https://doi.org/10.1007/BF03080135

Oreg, S., Vakola, M., \& Armenakis, A. (2011). Change recipients' reactions to organizational change A $60-y e a r$ review of quantitative studies. The Journal of Applied Behavioral Science, 47(4), 461-524. https://doi.org/10.1177/0021886310396550

Pillai, R., Schriesheim, C. A., \& Williams, E. S. (1999). Fairness perceptions and trust as mediators for transformational and transactional leadership: A two-sample study. Journal of Management, 25(6), 897-933. https://doi.org/10.1177/014920639902500606

Podsakoff, P. M., MacKenzie, S. B., \& Bommer, W. H. (1996). Transformational leader behaviors and substitutes for leadership as determinants of employee satisfaction, commitment, trust, and organizational citizenship behaviors. Journal of Management, 22(2), 259-298. https://doi.org/10.1177/014920639602200204

Preacher, K. J., \& Hayes, A. F. (2008). Asymptotic and resampling strategies for assessing and comparing indirect effects in multiple mediator models. Behavior Research Methods, 40(3), 879-891. https://doi.org/10.3758/BRM.40.3.879

Phong, L. B., Hui, L., \& Son, T. T. (2017). Developing creative culture and capable champions: An empirical study from Chinese firms. International conference - Creativity Development and Opportunities for Business and Startup Ideas (pp. 562-574), National University.

Phong, L. B., Hui, L., \& Son, T. T. (2018). The mediating role of knowledge sharing in linking transformational leadership and innovation. The 5th IBSM International Conference on Business, Management and Accounting, Hanoi University of Industry, Vietnam.

Rafferty, A. E., Jimmieson, N. L., \& Armenakis, A. A. (2013). Change readiness: A multilevel review. Journal of Management, 39(1), 110-135. https://doi.org/10.1177/0149206312457417

Ramezan, M., Sanjaghi, M. E., \& Rahimian Kalateh, H. (2013). Organizational change capacity and organizational performance: An empirical analysis on an innovative industry. Journal of Knowledge-Based Innovation in China, 5(3), 188-212. https://doi.org/10.1108/JKIC-07-2013-0012

Riggio, R. E., \& Bass, B. (2006). Transformational leadership. L. Erlbaum Associates. 
Rodell, J. B., \& Colquitt, J. A. (2009). Looking ahead in times of uncertainty: the role of anticipatory justice in an organizational change context. Journal of Applied Psychology, 94(4), 989. https://doi.org/10.1037/a0015351

Sengphet, P., Hui, L., \& Phong, L. (2019). The pathway to improve innovation capacity for Lao Firms: The roles of transformational leadership and psychological resources of employees. Journal of Business Administrative Studies, 5(2), 224-239. https://doi.org/10.20469/ijbas.5.10004-4

Smollan, R. K. (2013). Trust in change managers: the role of affect. Journal of Organizational Change Management, 26(4), 725-747. https://doi.org/10.1108/JOCM-May-2012-0070

Son, T. T., Phong, B. L., \& Thanh, T. L. (2021). The impacts of high-commitment HRM practices on exploitative and exploratory innovation: The mediating role of knowledge sharing. VINE Journal of Information Knowledge Management Systems (In press). https://doi.org/10.1108/VJIKMS-10-2020-0196

Son, T. T., Phong, L. B., \& Loan, B. T. T. (2020). Transformational leadership and knowledge sharing: determinants of firm's operational and financial performance. Sage Open, 10(2), 2158244020927426. https://doi.org/10.1177/2158244020927426

Son, T. T., Thang, T. Q., Cung, N. H., \& Phong, L. B. (2019). Building competitive advantage for Vietnamese firms: the roles of knowledge sharing and innovation. International Journal of Business Administration, 10(4), 1-12. https://doi.org/10.5430/ijba.v10n4p1

Soparnot, R. (2011). The concept of organizational change capacity. Journal of Organizational Change Management, 24(5), 640-661. https://doi.org/10.1108/09534811111158903

Tyler, T. R., \& Caine, A. (1981). The influence of outcomes and procedures on satisfaction with formal leaders. Journal of Personality and Social Psychology, 41(4), 642. https://doi.org/10.1037/0022-3514.41.4.642

Thomson, N. B., Rawson, J. V., Slade, C. P., \& Bledsoe, M. (2016). Transformation and transformational leadership: a review of the current and relevant literature for academic radiologists. Academic Radiology, 23(5), 592-599. https://doi.org/10.1016/j.acra.2016.01.010

Van, N. T., Phong, L. B., \& Loan, L. T. (2018). Antecedents of innovation capability: the role of transformational leadership and organizational learning. International Journal of Business Administration, 9(5), 1-10. https://doi.org/10.5430/ijba.v9n5p1

Wu, M., Huang, X., Li, C., \& Liu, W. (2012). Perceived interactional justice and trust-in-supervisor as mediators for paternalistic leadership. Management and Organization Review, 8(1), 97-121. https://doi.org/10.1111/j.1740-8784.2011.00283.x

Yang, Z., Nguyen, V. T., \& Le, P. B. (2018). Knowledge sharing serves as a mediator between collaborative culture and innovation capability: an empirical research. Journal of Business \& Industrial Marketing, 33(7), 958-969. https://doi.org/10.1108/JBIM-10-2017-0245

Yasir, M., Imran, R., Irshad, M. K., Mohamad, N. A., \& Khan, M. M. (2016). Leadership styles in relation to employees' trust and organizational change capacity: evidence from non-profit organizations. SAGE Open, 6(4), 2158244016675396. https://doi.org/10.1177/2158244016675396

Zainalipour, H., Fini, A. A. S., \& Mirkamali, S. M. (2010). A study of relationship between organizational justice and job satisfaction among teachers in Bandar Abbas middle school. Procedia-Social and Behavioral Sciences, 5, 1986-1990. https://doi.org/10.1016/j.sbspro.2010.07.401

\section{Copyrights}

Copyright for this article is retained by the author(s), with first publication rights granted to the journal.

This is an open-access article distributed under the terms and conditions of the Creative Commons Attribution license (http://creativecommons.org/licenses/by/4.0/). 